\title{
Methods of detection and ecological state evaluation of protective forest belts using complex ground survey and remote sensing data processing
}

\author{
L M Kavelenova ${ }^{1}$, E S Korchikov ${ }^{1}$, N V Prokhorova ${ }^{1}$, D A Terentyeva ${ }^{1}$ and \\ V A Fedoseev ${ }^{1,2}$
}

\begin{abstract}
${ }^{1}$ Samara National Research University, Moskovskoe Shosse 34, Samara, Russia, 443086
${ }^{2}$ Image Processing Systems Institute - Branch of the Federal Scientific Research Centre "Crystallography and Photonics" of Russian Academy of Sciences, Molodogvardeyskaya str. 151, Samara, Russia, 443001
\end{abstract}

\begin{abstract}
The protective forest belt system of Samara region consists of several components created from the late 19th to the early 20th century, in the middle of the 20th century, in the 60$70 \mathrm{~s}$ of the $20^{\text {th }}$ century, and more recent plantings. In the forest-steppe and steppe regions with a high level of agricultural transformations, the natural biological equilibrium of ecosystems is significantly disturbed. The protective forest belts play an important role in natural and anthropogenic landscapes conservation in Samara region. Because of numerous dispersed forest belt distribution throughout the Samara region territory, their different ownership and the lack of sufficient funds for their monitoring, it is difficult to organize belt state monitoring on the ground. The use of space imagery, which is processed during verification using data obtained from reference polygons, can help to overcome this situation. The peculiarity of forest belts as an extended object of relatively small width actualizes the task of developing the methods for their condition assessing. In this paper, some results of this work are analyzed for reference areas of field shelterbelts and roadside forest belts of the Samara region.
\end{abstract}

\section{Introduction}

In the forest-steppe and steppe regions with a high degree of land plowing, the natural biological equilibrium of ecosystems is significantly disturbed. In these regions, the protective man-created forest plantations seem to be here a sort of important connections between natural and anthropogenic landscapes. The forest belts reduce wind and water erosion by their participation in the redistribution of moisture and lowering of wind currents speed. When absorbing aerial pollution, they carry out its redistribution from air to phytomass and then to the soil environment, forming zones with increased accumulation of technogenic pollutants. The ecosystems developing on the basis of forest belts are also characterized by ambiguity. On the one hand, in conditions of the prevalence of agrocenoses, they become shelters of species of natural flora. On the other hand, introduced plant species used in the forest belts can spread in the environment beyond plantations, becoming agents of biological invasions. Nevertheless, the positive role of forest belts seems to be predominant, what makes necessary the realization of measures aimed at their preservation.

The system of protective forest belts of Samara region includes the components related to different periods of creation: from the late 19th to the early 20th century; in the middle of the 20th century; in 
the $60-70 \mathrm{~s}$ of the $20^{\text {th }}$ century; in the last decades of the $20^{\text {th }}$ century and first years of the 21 st. The first attempts to create forest belts in the Samara region were undertaken in 1872 but were not almost successful [1]. That time ash, yellow acacia, and oak trees were planted mainly on solonetsous soils that are of little use for afforestation, so most of the plantations were almost destroyed, remaining only 16\%. Later, in 1894-1897, about 60 hectares of forest belts, called "Timashevskie," were laid. Based on the results of these works, Nestor Genko, an enthusiast of national forestry, developed the basic provisions of agrotechnics for the regional plantations cultivation [2]. The watershed forest belts created under his leadership represent broad stripes of artificial forest with a width of more than 600 $\mathrm{m}$, located in the form of broken lines with the length from 2.5-3.5 to $25 \mathrm{~km}$ along the watersheds of rivers Samara and Chapaevka (Dubovskie and Teplovskie), Chapaevka and Chagry (Kamyshinskie , Bezenchukskie and Vladimirskie), Sok and Padovka (Shilanskie) [1, 2]. These forest belts stretch mainly from the southwest to the northeast, perpendicular to the direction of the dry winds and are divided by longitudinal, and every 80 to $200 \mathrm{~m}$ and by transverse clearings used as forest roads [1].

The surviving fragments of Genko forest belts, which are currently assigned the status of natural reserves, have been significantly transformed in comparison with the original plantations. The oldest specimens of trees were lost, and their place was taken by the individuals formed due to self-seeding, which led to a distortion of the rock composition of the strips. Ordinary placement of woody plants is also not completely traceable. The period of 1892-1906 accounts for the greatest amount of work on the creation of forest belts, in 1906 the planting was stopped, and then resumed only in 1949. It was precisely in 1949-1962 that the second large-scale period of the creation of forest shelterbelts called the "Stalin's plan for the transformation of nature" designed for 15 years. During this time, about 2 million hectares of forest shelterbelts were planted, the total length of which exceeded $5000 \mathrm{~km}$, and the direction was designed to block the way to the dry southeast winds. By 1952 the system was basically created and started working. The system of State forest belts along the reservoirs of the rivers the Northern Donets, the Volga and the Ural was divided into eight zones. Each of them consisted of 1 to 6 parallel narrow stripes of trees with 30 to 60 meters width, located at a distance of 300 meters from each other. On the territory of Samara region, the fourth zone begins, with a length of $580 \mathrm{~km}$, from Chapayevsk (not far from Samara), which stretches to Vladimirovka-on-Volga. According to the design, the strip consists of 4 parallel forest belts 60 meters wide and 300 meters between the bands [1, 3]. From 1966 to 1982, more than 3 thousand hectares of protective forest plantations per year were created annually. The last years of XX in Samara region were lost for new forest belts creation, but later such practice was revived (figure 1).

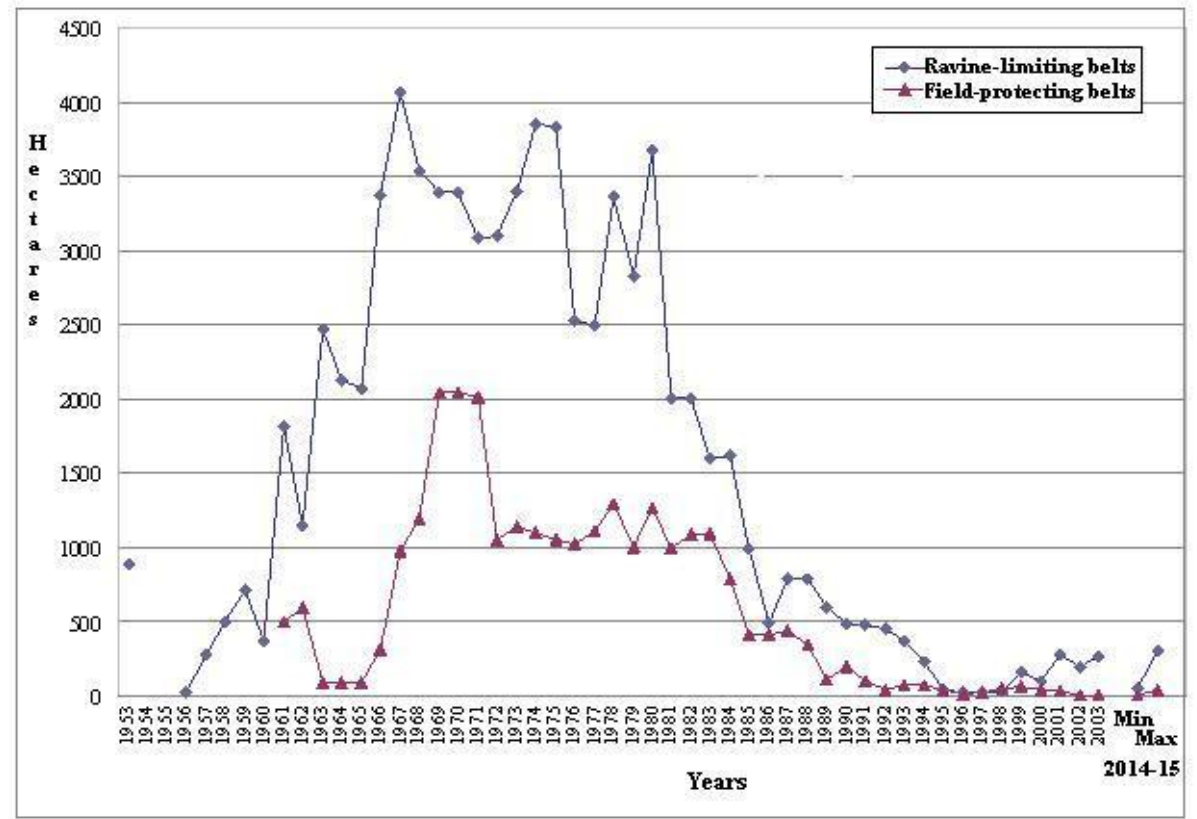

Figure 1. The dynamics of forest belts creation in Samara region (based on [1, 3]). 
According to the forest fund inventory, the total area of forest belts is more than 8.5 thousand hectares. Currently, forest belts are represented mainly by second-generation coppice stands, which resulted from clear cuttings. The average age is 55 years. Plantations of seed origin in the age of $90-$ 100 years occupy a smaller area, because in wartime were the only source of wood. Massively represented forest belts of "middle" age, both field-protective and roadside, are characterized by different life conditions of the stand. In recent years, there has been a clear trend towards the loss of birches in many plantations, for which the consistent impact of stressful conditions in the winter of 2009/2010. and subsequent drought in 2010 caused severe damage to the root systems. The dying of trees, which lasted for several years, resulted in the actual loss of a number of roadside belts with birch as the main tree species.

\section{Problem statement}

Because of the forest belts multiplicity and dispersed distribution over the entire territory of Samara region, also as their location on the different subordination lands, as well as the lack of sufficient funds for their monitoring, the organization of a ground survey of the forest belts current state is extremely unlikely. That is why it is expedient to use for this task remote sensing images which are very helpful in many other problems on vegetation analysis [4-6]. The peculiarity of forest belts as a linear extended object of relatively small width actualizes the task of developing methods for their detection and assessment of the state, including using the spectral characteristics of these plantations. In this paper, some results of this work are analyzed for reference areas of field shelterbelts and roadside forest belts of the Samara region.

\section{Brief review of field study results}

Three polygons were chosen as models taking into account their target membership (field, roadside) and species composition. Further, during the ground survey, the coordinates of the start and end points of the sites and their complex survey were coordinated, including the determination of the state of the plantations (figure 2):

1. "The environs of Bobrovka village" (located in the Kinelsky district, $3 \mathrm{~km}$ to the east of the village. Bobrovka, two reference plots of forest field shelterbelts reference plots 1,2). The forest belts are four-row plantations ( 2 - Fraxinus lanceolata, 2 - Ulmus glabra). The plot 1 is practically impassable, represents a continuous array of closed crowns, with separate downward-facing shrunken branches, withered trunks, light impregnations of trunks without bark. Planting is quite uniform, with a well-developed wood self-sowing from the north-west side, in the vegetative state it carries out active light absorption (with maxima in the red and blue regions of the spectrum). The plot 2 is rarefied, with "windows" and glades, which could have resulted from the death of a part of trees and due to unauthorized cuttings. Here also are the trunks of dead trees, facing the shrunken branches, The planting has inhomogeneous character, especially noticeable in the tier of crowns of the main rocks, will manifest itself in the features of the light absorption pattern.

2. "The environs of Formalny village" (located in the Kinelsky district in $2 \mathrm{~km}$ to the north-east of the Formalny village, 3 reference plots, one of which belonged to a group of field shelterbelts, and two to roadside strips (reference plots 1 - 3). The plot 1 (forest field shelterbelt) also is a four-row plantation with a relatively sparse arrangement of trees. On both sides of the strip, self-seeding of tree species is expressed, its strips do not reach $4 \mathrm{~m}$ in height. Planting openwork in the area of the crowns, in the lower part of the partially openwork, should give a relatively homogeneous pattern of light absorption. Plots 2 and 3 (fragments of the roadside strips) are also a four-row plantations (Betula pendula, Ulmus glabra, Betula pendula, Ulmus glabra). Plot 2 is characterized by irregular tree placement as a result of the death of individual specimens. The plantation is open-spaced in the crowns area, in the lower part is partially opened. The light absorption within the forest belt should give a non-uniform picture due to the loss of the woody places in places. Plot 3 in the result of a part of birches missing has glades in the tree layer. Partial filling of vacant places in the plantations occurs due to self-sowing and birch shoots originated from the trunks of weakened trees and individual stumps. For these roadside forest belts, we assumed future difficulties in distinguishing them from the images, which is due to their relatively small width $(<20 \mathrm{~m})$. 
3. "The environs of Malaya Malyshevka village" (located in the Kinel region, $6 \mathrm{~km}$ to the west of the Malaya Malyshevka village, four reference sites were laid, among which three belonged to the group of field shelterbelts, and one to roadside) (reference plots 1-4). Plot 1 is the forest belt is a plantation with a relatively uniform arrangement of trees, blown along the entire height. For plots 2 and three the high life state of birch trees as the main species were distinguished. Plot 4 as a fragment of a roadside forest belt, initially formed as a four-row plantation, is practically impassable now due to the windfall and the inclined crowns closing.

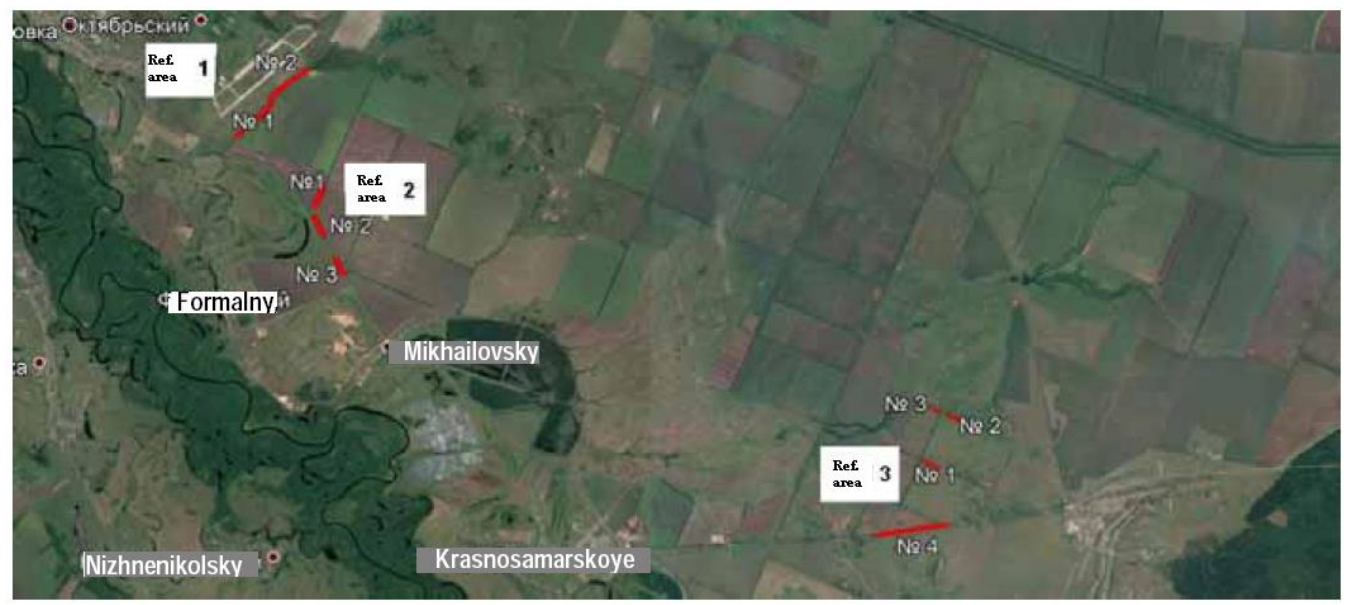

Figure 2. Scheme of the location of the forest belts reference areas: Reference area 1 - environs of Bobrovka village, Reference area 2 - the environs of Formalny village, Reference area 3 - environs of Malaya Malyshevka village.

\section{Detection of forest belts in space images}

Further, for this territory, the search for actual space images of spatial resolution as much as possible was carried out. As a result, fragments of images from the Resurs-P spacecraft obtained by the Geoton instrument with a resolution of 2.4 meters in four spectral channels (near infrared, red, green, and blue) were selected. The image size was $3158 \times 3159$ pixels and 10 bits per pixel. Due to the narrowness of the forest belts (about 10-15 m, as the survey showed), and also the predominantly mixed rock composition, the resolution of the Resource-P data (both spatial and spectral) was insufficient to classify the state of the belts (vitality of plantations). Therefore, the only problem of automatic detection of bands in the selected terrain from the available space images was considered.

For the detection of forest belts, we chose a technology consisting of two stages. At the first stage, a thematic classification of the territory into different types of the underlying surfaces was carried out to identify all areas of the forest. The second stage was devoted to the allocation of narrow forest belts among the found areas of the forest.

For the first stage of thematic classification, we used the previously developed technology [7], which includes the following main steps:

1. Pixel-wise preprocessing of input data using the combination of NAPC and PCA transformations.

2. Spatial preprocessing of input data through median filtering with a small window.

3. Classification procedure which takes into account both the cluster structure of data and spatial information. This procedure is based on k-means++ clustering followed by the connected components filling. The resulting regions were classified by majority voting.

4. Spatial post-processing of classification results using nonlinear filters.

The results of our previous studies [7] showed that the performance of this technology is the possibility of achieving high classification accuracy even in the case of a small training set selected from the spatially localized fragments of the analyzed image. It is convenient to use parts of the selected control and measuring polygons as such fragments, which should be supplemented with examples of other samples of the underlying surface. 
In our investigation, this technology was compared with a classification algorithm based on hierarchical histograms [8]. This algorithm analyzes a feature vector structure and performs the construction of a hierarchical histogram of the training sample at the learning stage. The histogram is stored in the form of an unbalanced fixed-depth tree, each node of which contains information about the frequency of sample objects that hit the interval of the histogram given by this node. As a result of the truncation of the tree by the principle of node preservation, the frequency of the hit of the sampling elements is greater than a given threshold, the generalizing ability of the classifier is ensured. At the classification stage, the cell of the hierarchical histogram to which the feature vector belongs is determined, and the pixel is included in the class with the maximum frequency of the training sample elements entering this cell. Pixels for which the histogram cell was not found are included in the additional class "not classified".

Figure 3a shows a fragment of an image from the Resurs-P satellite (the Geoton sensor) that contains a part of the analyzed territory including the selected measuring polygons.

To evaluate the classification quality, we prepared manually a ground-truth markup of the territory which includes six classes of the underlying surface: asphalt, forest and various types of crops (see figure $3 b$ ). The amount of the marked data is about a half of all pixels at the image. As can be seen from figure $3 \mathrm{a}$, the forest class is represented by forest belts bordering fields, small forest areas at the upper part and at the lower part, on the banks of small reservoirs.

a)

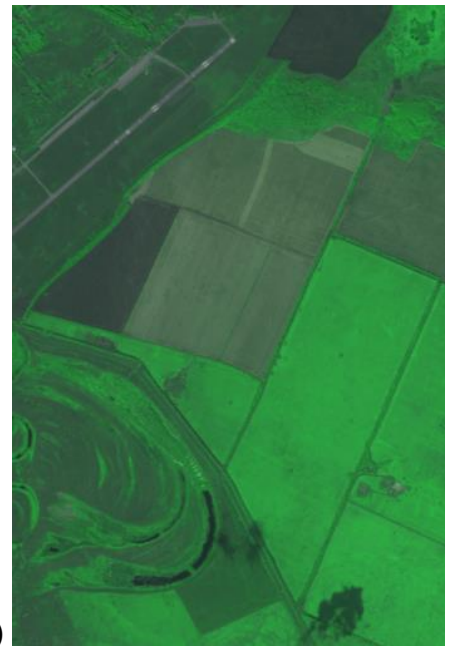

b)

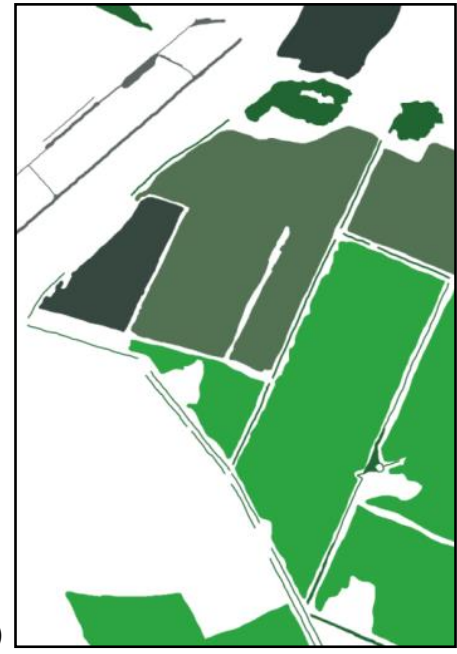

Figure 3. The analyzed satellite image of the satellite with Resurs-P (a) and the marking of the main classes of the underlying surface (b).

Figure 4a shows the results of the automatic classification of this image using the selected technology. The training sample is formed from the pixels of localized areas, and its size is $1 \%$ of the all marked pixels in figure $3 \mathrm{~b}$. Figure $4 \mathrm{~b}$ gives the results of the pixel-wise classification for comparison. The chosen technology provides a higher quality solution to the problem. The numerical estimation of the classification accuracy calculated for all the marked data was $95 \%$ for the figure $4 a$.

\section{Detection of forest among the found forest areas}

In figure 5a, areas classified as forests are marked black. Further, we need to distinguish forest belts among these areas. Forest belts are characterized by narrowness and consist of long straight sections. To find them, we first applied the following mathematical morphology operations [9]:

1. Closing with a small window to merge separated fragments of forest belts.

2. Opening with a window exceeding the maximum forest belt width, to remove all the belts.

3. Subtraction of the step 2 result from the step 1 result.

As a result of these operations, fragments of forest belts and groves, comparable to them in width, should remain on the image, as shown in figure $5 \mathrm{~b}$. 
a)

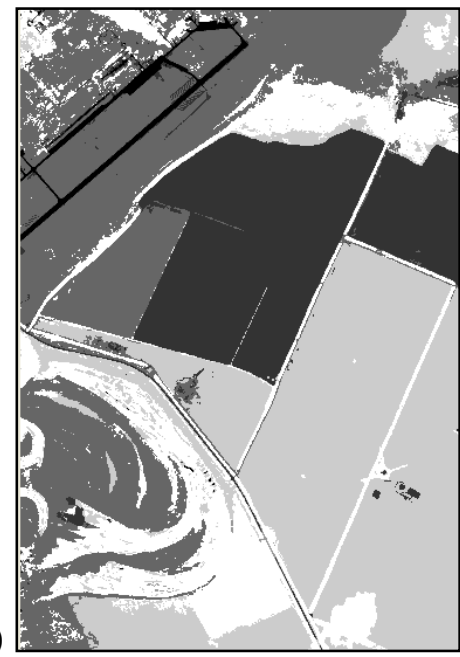

b)

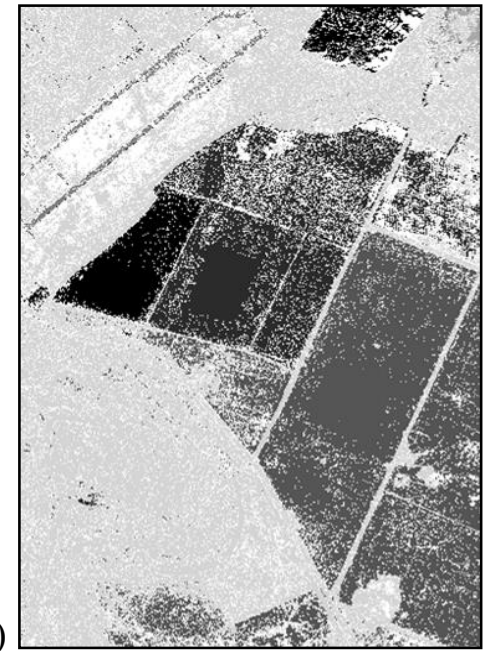

Figure 4. Classification results of the image in Figure 3a: (a) using the selected technology, (b) using pixel-wise classification.

Next, to reveal linear fragments from the remaining objects, we used Hough transform [9]. On the Hough spectrum, we found local maxima corresponding to the most vivid linear components. The coordinates of the obtained maxima uniquely determine the straight lines. Their intersection with the regions selected in figure $5 \mathrm{~b}$ allowed to determine the ends of the desired segments, which ideally should coincide with the boundaries of the forest belts. The final results are depicted in figure 6 (the segments are marked in red). One can see that despite some false segments all the required forest belts of sufficient width (more than 8 pixels in the given Geoton image that corresponds to 20 meters on the ground) were successfully found.

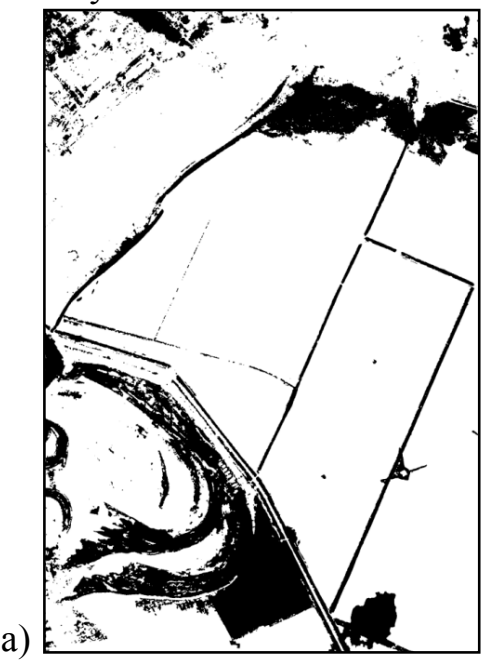

b)

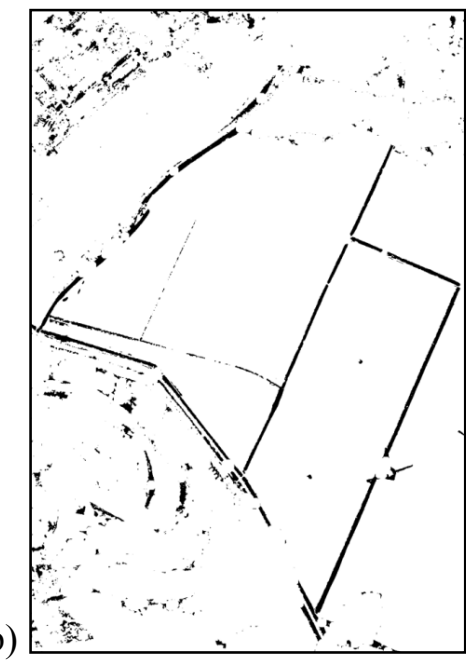

Figure 5. Forest areas (a) and the result of their morphological processing (b).

\section{Conclusion}

In this paper, we presented the results of forest belt detection on satellite imagery. This problem is part of a practically meaningful study aimed at assessing the ecological state of forest belts in the Samara region. To solve this problem, a two-stage method was used, consisting of thematic classification of remote sensing data to identify forest areas and subsequent detection of forest belts from the classification results. The belt detection stage was performed using a technique based on mathematical morphology and Hough transform. To get the data used in this study, a field survey was conducted, as a result of which control and measurement polygons were identified, the coordinates of which were subsequently used for numerical evaluation of the quality of the solution of the classification problem. The obtained results after analysis of four-channel images with a spatial resolution of $2.4 \mathrm{~m}$ allow us 
to conclude that the selected technique can be used to solve the problem of finding forest belts. For the subsequent analysis of the ecological state of plantations, data having a greater spatial and spectral resolution are required.

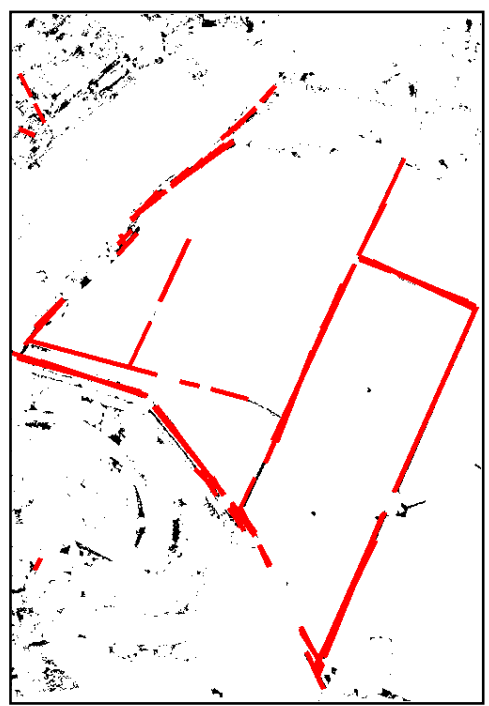

Figure 6. Results of forest belt detection.

\section{References}

[1] Shabalin I M 2005 The Samara forest (Samara)

[2] Pajusova T V 2010 "Green Bastions" by Nestor Genko Samara Luke: Problems of Regional and Global Ecology 4 177-182

[3] Kazantsev I V and Matveeva T B 2016 Ecological state of forest belts in the Samara region New science - from idea to result: International scientific periodical on the results of the International Scientific and Practical Conference, Surgut 5-8

[4] Afanasyev A A and Zamyatin A V 2017 Hybrid methods for automatic landscape change detection in noisy data environment Computer Optics 41(3) 431-440 DOI: 10.18287/24126179-2017-41-3-431-440

[5] Terekhin E A 2017 Recognition of abandoned agricultural lands using seasonal NDVI values Computer Optics 41(5) 719-725 DOI: 10.18287/2412-6179-2017-41-5-719-725

[6] Vorobiova N S, Sergeyev V V and Chernov A V 2016 Information technology of early crop identification by using satellite images Computer Optics 40(6) 929-938 DOI: 10.18287/24126179-2016-40-6-929-938

[7] Fedoseev V A 2018 Hyperspectral satellite image classification using small training samples from the image itself Journal of Physics: Conference Series (in print)

[8] Denisova A Y and Sergeyev V V 2017 Supervised multichannel image classification algorithm using hierarchical histogram representation Procedia Engineering 201 213-222

[9] Gonzalez R C and Woods R E 2009 Digital Image Processing (Pearson Education)

\section{Acknowledgments}

This work was supported by the Russian Foundation for Basic Research (grants 16-29-09494 ofi_m, 18-07-00748 a), by Project 5-100, and the Federal Agency for scientific organizations (Agreement 007-GZ/43363/26). Satellite images of the apparatus "Resurs-P" are provided by JSC RCC "Progress". 